\title{
IMPLEMENTATION OF EUROPEAN UNION GREEN INDUSTRIAL POLICY AND REGULATION IN NORTH MACEDONIA
}

\author{
Zoran Sapuric $^{1^{*}}$, Filip Ivanovski ${ }^{1}$, Vladimir Naumovski ${ }^{1}$ \\ I*University American College, Skopje, North Macedonia; \\ "Email: sazoran@hotmail.com;
}

Received May 2020; Accepted June 2020; Published July 2020;

DOI: https://doi.org/10.31407/ijees10.310

\begin{abstract}
Industry has an important role for the economy. Contemporary industrial policy and regulation are closely linked with the environment. Almost all industrial sectors cause threats to the environment in all phases such as: projecting, designing, preparation, supplying with raw materials, manufacturing, energy consumption, assembling, storage, packaging, transport, and usage of final products and all other phases of life circulation of the products. This produces a number of dangers for the environment. Implementation of environmental policy and regulation leads to creation of green economy and green industry which means that modern industry production has to satisfy environmental standards according to the principles of sustainable development. North Macedonian, as candidate state for a membership of the EU started to transpose EU environmental legal regulation and policy in 2004. This results with stipulation of standards that lead to the environmentally friendly green industry. Also, there are adopted strategic documents in the field of industrial policy that are in compliance with the environmental requirements. The problems appear with practical implementation and industrial sector is not completely harmonized with environmental standards, even there are some positive results. Implementation of environmental standards requires significant financial recourses which should be provided by industrial sector, international donors at the first place from EU funds and state authorities. The main aim of this paper is to analyze the relations between industrial policy and regulation in North Macedonia from the aspect of environment and its harmonization with EU practices, regulation and standards. Additional aim is to give some recommendations.
\end{abstract}

Key words: industrial policy, environment, regulation, standards European Union. 